Bull. Chem. Soc. Ethiop. 2016, 30(3), 369-376.

Printed in Ethiopia

DOI: http://dx.doi.org/10.4314/bcse.v30i3.5

ISSN 1011-3924

(c) 2016 Chemical Society of Ethiopia

\title{
ADSORPTION OF POLYNUCLEAR AROMATIC HYDROCARBONS FROM AQUEOUS SOLUTION: AGROWASTE-MODIFIED KAOLINITE VS SURFACTANT MODIFIED BENTONITE
}

\author{
Emmanuel I. Unuabonah ${ }^{1}$, Bamidele I. Olu-Owolabi ${ }^{2 *}$, Leonard Böhm ${ }^{3}$ and Rolf-Alexander \\ Düring ${ }^{3}$ \\ ${ }^{1}$ College of Natural Sciences, Department of Chemical Sciences, Redeemer's University, Ogun \\ State, Nigeria \\ ${ }^{2}$ Department of Chemistry, University of Ibadan-Nigeria \\ ${ }^{3}$ Institute of Soil Science and Soil Conservation, Research Centre for BioSystems, Land Use and \\ Nutrition (IFZ), Justus Liebig University Giessen, Giessen-Germany
}

(Received August 21, 2014; revised November 4, 2016)

\begin{abstract}
The adsorption efficiency of a new hybrid clay adsorbent for polynuclear aromatic hydrocarbons (PAHs) is compared with known modified clay adsorbents. The new hybrid clay adsorbent (HYCA) showed far higher adsorption capacities for the adsorption of various PAH molecules compared with sodium dodecyl sulfate modified and humic acid modified Bentonite clay adsorbents. With the new hybrid clay adsorbent (HYCA), the adsorption of some of the larger PAH molecules was complete in the first $1 \mathrm{~h}$ as compared with $\approx 62 \%$ and $\approx 76 \%$ observed for both humic acid modified and sodium dodecyl sulfate modified Bentonite clay adsorbents respectively. In $24 \mathrm{~h}$ adsorption of the PAHs was complete for all adsorbents with HYCA adsorbent showing better efficiency in the removal of the PAH molecules from aqueous solutions. No significant change was observed with increase in time up to $48 \mathrm{~h}$. The adsorption was observed to be more spontaneous with HYCA adsorbent than with either modified Bentonite adsorbents. The enthalpy of adsorption did not follow any specific order and were not consistent for all PAH molecules considered.
\end{abstract}

KEY WORDS: Adsorption, Polynuclear aromatic hydrocarbons, Enthalpy, Hybrid clay, Bentonite

\section{INTRODUCTION}

Polynuclear aromatic hydrocarbons (PAHs) are persistent toxic pollutants consisting of two or more fused benzene rings. They are a product of incomplete combustion of hydrocarbons and other organic matters such as coal, petroleum and biomass. PAHs are introduced into the environment through atmospheric deposition, industrial and/or municipal effluent discharges, and agricultural runoffs. They are easily transported over a long distance in aquatic medium because of their stable aromatic structure [1].

Methods that have been employed to mitigate these toxic pollutants from aquatic environment include permanganate and ozone oxidation [2], photocatalysis [3-5], biodegradation [6], adsorption [7, 8], etc. However, adsorption method has become widely used because of its simple and cost-effective approach. Various adsorbents have been prepared in the past for the removal of PAHs from aqueous solutions. They include activated carbon [9], resins [10], carbon nanomaterials [11] and Bentonite [8]. However, these adsorbents, which generally exist in the form of powders or particles, are difficult to be recycled from water, thus restricting their practical application in water treatment.

This study presents a new hybrid clay adsorbent which is a composite of both Bentonite clay and an agricultural waste (Carica papaya seeds). This adsorbent has been recently used in the adsorption some heavy metal ions and was proven to have high adsorption efficiency for these metal ions [12]. The effect some operating variables (temperature, initial adsorbate

*Corresponding author. E-mail: iromidayobamidele@yahoo.co.uk 
concentration and contact time) in the adsorption of these PAHs onto the various adsorbents were studied.

\section{EXPERIMENTAL}

\section{Preparation of modified clays}

Surfactant modified Bentonite. Six grams of Bentonite clay was weighed into a clean beaker and $50 \mathrm{~mL}$ of $0.05 \mathrm{M}$ sodium dodecyl sulfate (SDS) was added and the mixture stirred with a magnetic stirrer for $2 \mathrm{~h}$. The organo-modified clay was then separated from the mixture by vacuum filtration, washed several times with milli $\mathrm{Q}$ water, dried at $110{ }^{\circ} \mathrm{C}$ for $6 \mathrm{~h}$ and ground to pass through 200-mesh. This sample is henceforth referred to as SB sample.

Humic acid modified Bentonite. Known mass of humic acid (2.5 g) was added to known mass of Bentonite $(47.5 \mathrm{~g})$. This mixture was suspended in $0.001 \mathrm{M}$ sodium nitrate and agitated for five days at $25{ }^{\circ} \mathrm{C}$. The mixture was later centrifuged and the supernatant decanted. Thereafter, the sample was dried at $50{ }^{\circ} \mathrm{C}$ pulverized and sieved through $0.5 \mathrm{~mm}$ sieve. This sample is henceforth referred to as $\mathrm{HB}$ sample.

Hybrid clay synthesis. Equal weights (10 g each) of purified clay and dried papaya seeds were weighed into a $500 \mathrm{~mL}$ beaker with $200 \mathrm{~mL}$ of $0.1 \mathrm{M} \mathrm{NaOH}$ and stirred. The mixture was left standing for 3 days with intermittent stirring after which it was transferred into an oven and heated at $105{ }^{\circ} \mathrm{C}$ until dried. Samples of the dried mixture were weighed into crucibles and calcined at $300{ }^{\circ} \mathrm{C}$ for $6 \mathrm{~h}$ in air. The resulting dark powdery material was washed several times with Millipore water to remove residual $\mathrm{NaOH}$ from the surface of the composite and subsequently dried to remove all moisture. The dried sample was stored in an airtight container and subsequently referred to as HYCA adsorbent.

\section{Effect of time}

A known mass of the surfactant modified Bentonite, humic acid modified Bentonite and papaya seed modified kaolinite $(50 \mathrm{mg})$ ) was weighed into different glass bottles. Twenty milliliters (20 $\mathrm{mL})$ of $0.01 \mathrm{M} \mathrm{CaCl}_{2}$ and $2 \mu \mathrm{L}(2 \mu \mathrm{L} \approx 10 \mathrm{ppb})$ each of PAHs were added. Samples were agitated at room temperature and were removed from the shaker at different time intervals. After equilibration, analysis was carried out using solid phase micro-extractor (SPME) coupled with gas chromatography-mass spectrometer (GC-MS).

\section{Adsorbate concentration}

A range of concentrations $(0-50 \mathrm{ppb})$ were prepared. Known volume of each of these concentrations was added to $100 \mathrm{mg}$ each of the modified clays and $50 \mathrm{mg}$ of hybrid clay. The volume was made up to $20 \mathrm{~mL}$ by $0.01 \mathrm{M} \mathrm{CaCl}_{2}$. The suspensions were agitated for $24 \mathrm{~h}$. After equilibration, the amount of PAHs left in solution was determined using solid phase microextractor (SPME) coupled with gas chromatography-mass spectrometer (GC-MS). This procedure was repeated for adsorption at $40{ }^{\circ} \mathrm{C}$.

\section{Thermodynamics of adsorption}

The enthalpy of adsorption ( $\Delta H^{o}$ ) PAHs onto the various adsorbents were determined using the Van't Hoff equation given as:

$\ln \left(\frac{K_{T 1}}{K_{T 2}}\right)=\frac{\Delta H^{o}}{R}\left(\frac{1}{T_{1}}-\frac{1}{T_{2}}\right)$ 
The Gibbs free energy ( $\Delta G^{o}$ ) data were determined using the equation:

$\Delta G^{o}=-R T \ln K$

Langmuir-Freundlich model

Langmuir model, (Langmuir, 1918) stated that at constant temperature, metal ions held onto the biomass will be in equilibrium with metal ions in bulk solution. The saturated monolayer isotherm can be represented as:

$q_{e}=\frac{q_{\max }\left(k_{a} C_{e}\right)^{n_{s}}}{1+\left(k_{a} C_{e}\right)^{n_{s}}}$

where $C_{e}$ is the equilibrium concentration $(\mathrm{mg} / \mathrm{L}) ; q_{e}$ is the amount of PAHs adsorbed $(\mathrm{mg} / \mathrm{g})$; $q_{\max }$ is the complete monolayer adsorption capacity $(\mathrm{mg} / \mathrm{g}) ; k_{a}$ is adsorption equilibrium constant $(\mathrm{L} / \mathrm{mg})$ and $n_{s}$ is the Freundlich constant parameter.

All equlibrium plots were made using KyPlot version 2.0 software.

\section{RESULTS AND DISCUSSION}

\section{Modification of clays}

The surfactant, SDS, used in this work is an anionic structural surfactant soluble in water. There are three possibilities of interactions between negative charge-carrying Bentonite clay particles and the anionic surfactant. First, it is possible that ion exchange can take place between $\mathrm{OH}^{-}$ ions on clay surfaces and the anionic part of surfactants. Second, H-bonds can form between clay particles and surfactant molecules. Third, it is possible that $\mathrm{Ca}^{2+}$ cation can establish electrostatic bridges between the anionic part of surfactants and the surface of clay particles [13]. Previous studies on the modification of Bentonite clay [14] suggest that the cation exchange capacity (120 meq/100 g with a surface area of $\left.77 \mathrm{~m}^{2} / \mathrm{g}\right)$ of humic acid modified Bentonite is greater than those of unmodified Bentonite $(95 \mathrm{meq} / 100 \mathrm{~g}$ with a surface area of 80 $\mathrm{m}^{2} / \mathrm{g}$ ). HYCA adsorbent has been shown to be a composite with the crystal structure of the clay component not significantly affected by the addition of a biomass (Carica papaya seeds). It has a cation exchange capacity and surface area of ca. $75 \mathrm{meq} / 100 \mathrm{~g}$ and ca. $9 \mathrm{~m}^{2} / \mathrm{g}$ (BET surface area), respectively [12].

\section{Effect of increasing concentration}

At $20{ }^{\circ} \mathrm{C}$, increasing concentration was found to increase the amount of PAHs adsorbed per gram of adsorbent using the non-linear Langmuir-Freundlich isotherm model to model experimental data (Table 1). Both Freundlich and Langmuir models were not found suitable to describe the adsorption data obtained in this study. With sodium dodecyl sulfate modified Bentonite, adsorption capacity increased with increasing molecular weight of the various PAHs while the reverse was observed for HB. The reason for this could be the blockage of the interlayer spaces of the Bentonite (which can accommodate the lower PAHs) by the surfactant such that the available free space to accommodate the lower PAHs was largely reduced in SB sample.

The adsorption capacities of HB for the higher PAHs decreased as a result of the hydrophilic nature introduced by the humic acid on the Bentonite surface. Olu-Owolabi et al. [14] reported that the surface of humic Bentonite is characterised by caboxylic and hydroxyl ions. 
Table 1. Equilibrium parameters for the adsorption of PAHs onto HYCA, HB and SB modified adsorbents at $20^{\circ} \mathrm{C}$.

\begin{tabular}{|c|c|c|c|c|}
\hline & $\mathrm{q}_{\max }(\mu \mathrm{g} / \mathrm{g})$ & $\mathrm{k}_{\mathrm{a}}(\mathrm{L} / \mathrm{g})$ & $\mathrm{n}_{\mathrm{s}}$ & $\mathrm{r}^{2} / \mathrm{K}_{\mathrm{d}}\left(\mathrm{kg} \mathrm{L}^{-1}\right)$ \\
\hline \multicolumn{5}{|c|}{ Napthalene } \\
\hline SB & 2.53 & 0.0004 & 0.35 & $0.9801(0.04)$ \\
\hline HB & 5.00 & 0.05 & 8.82 & $0.9663(0.04)$ \\
\hline HYCA & 18.8 & 0.22 & 4.76 & $0.9986(1.56)$ \\
\hline \multicolumn{5}{|c|}{ Acenaphthalene } \\
\hline SB & 3.73 & 0.04 & 27.6 & $0.9936(0.13)$ \\
\hline HB & 7.93 & 0.11 & 3.39 & $0.9956(0.16)$ \\
\hline HYCA & 17.23 & 0.33 & 2.94 & $0.9852(2.13)$ \\
\hline \multicolumn{5}{|c|}{ Acenaphthene } \\
\hline SB & 1.91 & 0.04 & 7.10 & $0.9047(0.07)$ \\
\hline $\mathrm{HB}$ & 14.0 & 0.06 & 0.97 & $0.9989(0.25)$ \\
\hline HYCA & 21.5 & 0.44 & 2.53 & $0.9975(3.85)$ \\
\hline \multicolumn{5}{|c|}{ Fluorene } \\
\hline SB & 3.86 & 0.07 & 1.78 & $0.9793(0.18)$ \\
\hline HB & 11.0 & 0.15 & 2.08 & $0.9999(0.30)$ \\
\hline HYCA & 9.71 & 0.58 & 9.09 & $0.9989(2.13)$ \\
\hline \multicolumn{5}{|c|}{ Phenanthrene } \\
\hline SB & 5.57 & 0.09 & 2.64 & $0.9928(0.44)$ \\
\hline HB & 11.0 & 0.20 & 2.53 & $0.9980(0.35)$ \\
\hline HYCA & 32.2 & 0.03 & 0.93 & $0.9905(0.89)$ \\
\hline \multicolumn{5}{|c|}{ Anthracene } \\
\hline SB & 5.70 & 0.17 & 0.97 & $0.9730(0.85)$ \\
\hline $\mathrm{HB}$ & 10.2 & 0.28 & 2.34 & $0.9907(0.35)$ \\
\hline HYCA & 19.8 & 1.41 & 12.4 & $0.9999(10.6)$ \\
\hline
\end{tabular}

$K_{d}=$ distribution coefficient which is an average of the ratio of the adsorption capacity $\left(q_{e}\right)$ at equilibrium and the concentration of PAHs in equilibrium solution $\left(C_{e}\right)$.

HYCA sample on the other hand showed strong preference for the higher molecular weight compounds without any specific order. It has been suggested by Bi et al. [15] that non-specific interactions (van der Waal forces) is mainly responsible for hydrophobic type interaction of PAH compounds with adsorbent surfaces.

The modified bentonite adsorbents (HB and SB adsorbents) generally showed increased adsorption capacity with increasing molecular weight of the various PAHs with HYCA adsorbent presenting a stronger preference for the PAHs than either of the modified Bentonite adsorbents. These modified adsorbents appeared to show higher adsorption capacity for higher molecular weight compounds without any specific order.

It is further observed that adsorption of these modified clays for two structurally similar PAHs like acenaphthalene and acenaphthene differs. The SB modified clay has higher adsorption capacity for alternant aromatic compound like acenaphthalene (which are more soluble and have the ability to sustain induced electron ring current) as compared with the nonalternant aromatic compound (acenaphthene) [16]. However, both HB and HYCA samples prefer the non-alternant aromatic compound (acenaphthene) indicating that both samples may have better hydrophobicity when compared with the SB sample. With phenanthrene and anthracene (with same molecular weight), both HB and HYCA samples prefer the phenanthrene even though it is more soluble in aqueous media (Table 1).

\section{Effect of temperature}

With increase in temperature from $20{ }^{\circ} \mathrm{C}$ to $40{ }^{\circ} \mathrm{C}$, there was an observed decrease in the adsorption capacities of SB and HA adsorbents for the adsorption of PAHs which is reflected in 
the exothermic nature of the adsorption process (Tables 1, 2 and 3). The HYCA sample showed a general decrease in adsorption capacity for PAHs with increase in temperature (Tables 1 and 2) as supported by the observed shift of adsorption from endothermic to exothermic adsorption process (Table 3). This suggests that adsorption of the various PAHs onto SB and HB adsorbents was not favourable with increasing temperature (up till the temperature limit of $40{ }^{\circ} \mathrm{C}$ used in this study).

Table 2. Equilibrium parameters for the adsorption of PAHs onto HYCA, HB and SB modified adsorbents at $40{ }^{\circ} \mathrm{C}$

\begin{tabular}{|c|c|c|c|c|}
\hline & $\mathrm{q}_{\max }(\mu \mathrm{g} / \mathrm{g})$ & $\mathrm{b}(\mathrm{L} / \mathrm{g})$ & $n_{s}$ & $\mathrm{r}^{2} /\left(\mathrm{K}_{\mathrm{d}}\left(\mathrm{L} \mathrm{kg}^{-1}\right)\right.$ \\
\hline \multicolumn{5}{|c|}{ Napthalene } \\
\hline SB & 1.76 & 0.04 & 1.93 & $0.9953(0.03)$ \\
\hline $\mathrm{HB}$ & 4.61 & 0.04 & 12.3 & $0.9828(0.03)$ \\
\hline HYCA & 8.58 & 0.01 & 1.03 & $0.9987(0.08)$ \\
\hline \multicolumn{5}{|c|}{ Acenaphthalene } \\
\hline SB & 1.42 & 0.06 & 3.83 & $0.9897(0.03)$ \\
\hline $\mathrm{HB}$ & 7.81 & 0.06 & 6.90 & $0.9766(0.10)$ \\
\hline HYCA & 12.1 & 0.04 & 1.65 & $0.9998(0.22)$ \\
\hline \multicolumn{5}{|c|}{ Acenaphthene } \\
\hline SB & 1.69 & 0.06 & 3.24 & $0.9669(0.04)$ \\
\hline $\mathrm{HB}$ & 8.76 & 0.06 & 3.67 & $0.9745(0.10$ \\
\hline HYCA & 17.3 & 0.03 & 1.56 & $0.9935(0.26)$ \\
\hline \multicolumn{5}{|c|}{ Fluorene } \\
\hline SB & 3.33 & 0.07 & 3.35 & $0.9907(0.09)$ \\
\hline $\mathrm{HB}$ & 8.62 & 0.17 & 2.31 & $0.9768(0.22)$ \\
\hline HYCA & 25.6 & 0.03 & 1.28 & $0.9982(0.47)$ \\
\hline \multicolumn{5}{|c|}{ Phenanthrene } \\
\hline SB & 5.60 & 0.11 & 2.83 & $0.9841(0.22)$ \\
\hline $\mathrm{HB}$ & 8.57 & 0.22 & 5.66 & $0.9838(0.26)$ \\
\hline HYCA & 21.3 & 0.11 & 2.29 & $0.9908(0.87)$ \\
\hline \multicolumn{5}{|c|}{ Anthracene } \\
\hline SB & 5.46 & 0.14 & 3.03 & $0.9866(0.22)$ \\
\hline $\mathrm{HB}$ & 11.6 & 0.15 & 1.80 & $0.9636(0.33)$ \\
\hline HYCA & 28.1 & 0.09 & 1.67 & $0.9988(0.87)$ \\
\hline
\end{tabular}

$K_{d}=$ distribution coefficient which is an average of the ratio of the adsorption capacity $\left(q_{e}\right)$ at equilibrium and the concentration of PAHs in equilibrium solution $\left(C_{e}\right)$.

Table 3. Thermodynamic parameters for the adsorption of PAHs onto HYCA, HB and SB modified adsorbents.

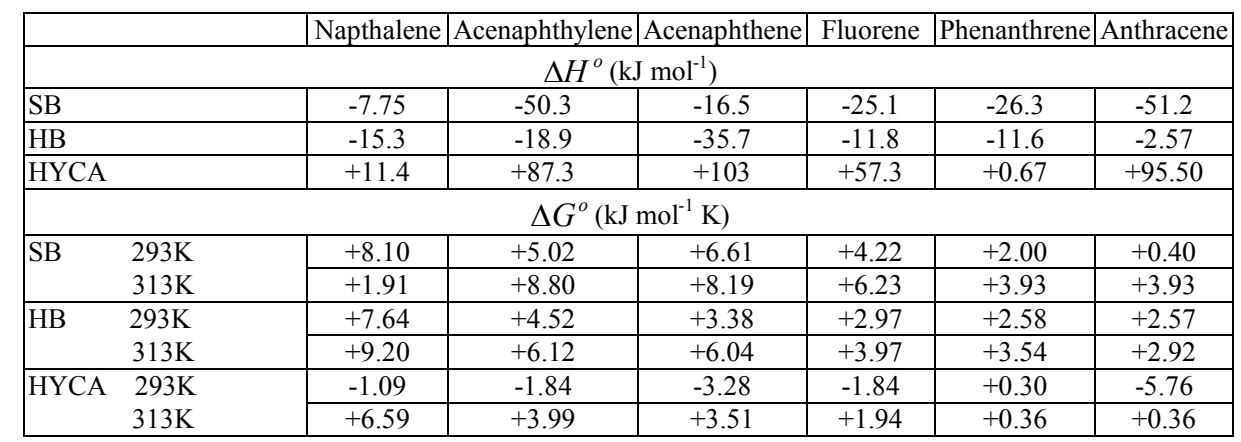


Temperature seems to also have an effect on the distribution coefficients of the various PAHs onto the different adsorbents (Tables 1 and 2) where $K_{d}$ values were observed to decrease with increasing temperature. However, $K_{d}$ values were not strictly consistent with adsorption capacities values of the various adsorbents for the PAHs.

The decreased adsorption capacity of HYCA adsorbent with increased temperature could be attributed to increasing water solubilities of PAHs in the presence of HYCA or increased organic carbon on the HYCA adsorbent as compared with the other two modified Bentonite adsorbents [17-19].

Adsorption of PAHs onto modified Bentonite adsorbents was non-spontaneous and generally not feasible and these increased with increase in temperature (Table 3). However, adsorption of PAHs onto HYCA adsorbent was spontaneous and feasible. The spontaneity and feasibility decreased with increasing temperature.

\section{Effect of time}

From Figures 1 and 2, adsorption of PAHs onto HYCA adsorbent was virtually complete within the first $1 \mathrm{~h}$ for most of the larger PAHs used in this study while smaller PAH molecules like naphthalene and acenaphthylene were $\geq 86.6 \%$ adsorbed within this time. For SB and HA samples (Figures 2 and 3) the adsorption of PAHs were less than what were adsorbed onto HYCA adsorbent within the first $1 \mathrm{~h}$. Adsorption was observed to reach equilibrium at $24 \mathrm{~h}$ for all adsorbents. No significant change was observed with increase in time up to $48 \mathrm{~h}$.

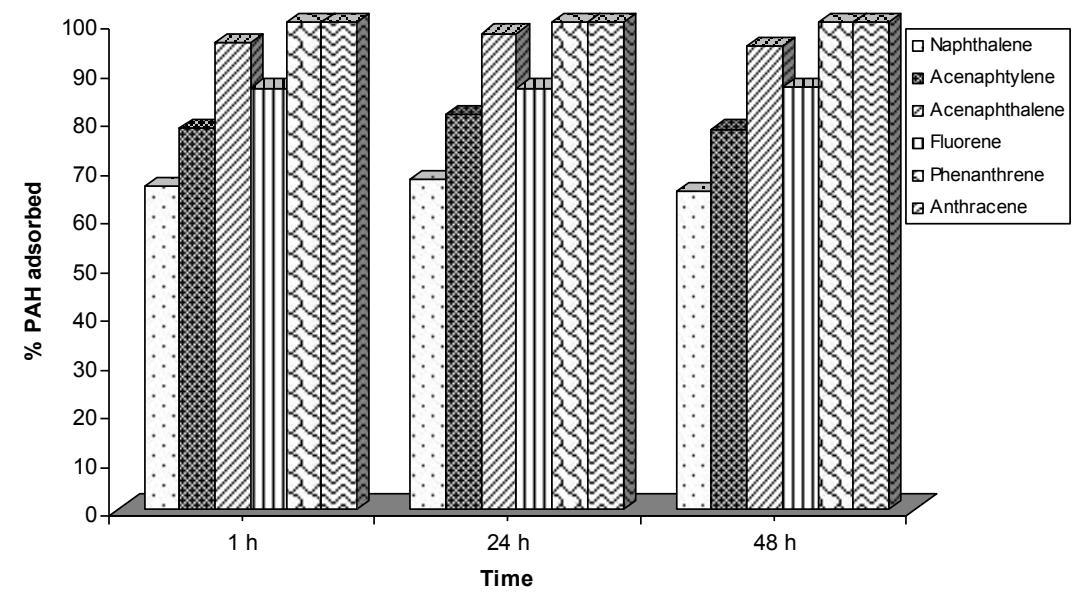

Figure 1. Effect of time on the adsorption of PAHs onto hybrid clay adsorbent.

Adsorption mechanism

It was also suggested by $\mathrm{Bi}$ et al. [15] that non-specific interactions (van der Waal forces) is mainly responsible for hydrophobic type interaction of PAH compounds with adsorbent surfaces. Gaboriau and Saada [20] also suggested that partitioning of a polar solutes like the PAHs between two phases can be described by the solvophobic theory. For humic modified adsorbents, Conte et al. [21], Pan et al. [22], and Terashima et al. [23] have suggested that the adsorbed humic acid increase the number of hydrophobic sites for the adsorption of PAHs using the $\pi-\pi$ electron-donor acceptor (EDA) interaction which is the reason for the better adsorption capacity of HB sample for PAHs in this study over SB sample [24, 25] which is likely to use $\pi^{+}-\pi$ EDA interaction common with cationic amines [26]. HYCA was observed to have far 
better adsorption efficiency for these PAHs compared with surfactant modified Bentonite (Tables 1 and 2) or even unmodified kaolinite (result not shown). However, it is possible to have this $\pi-\pi$ EDA interaction between the PAHs with adsorbents that are carbonaceous in nature which is the likely mechanism of adsorption of PAHs onto HYCA adsorbent [27]. While HYCA adsorbent serves as $\pi$-accepting substituents the PAHs are considered $\pi$-donors [26].

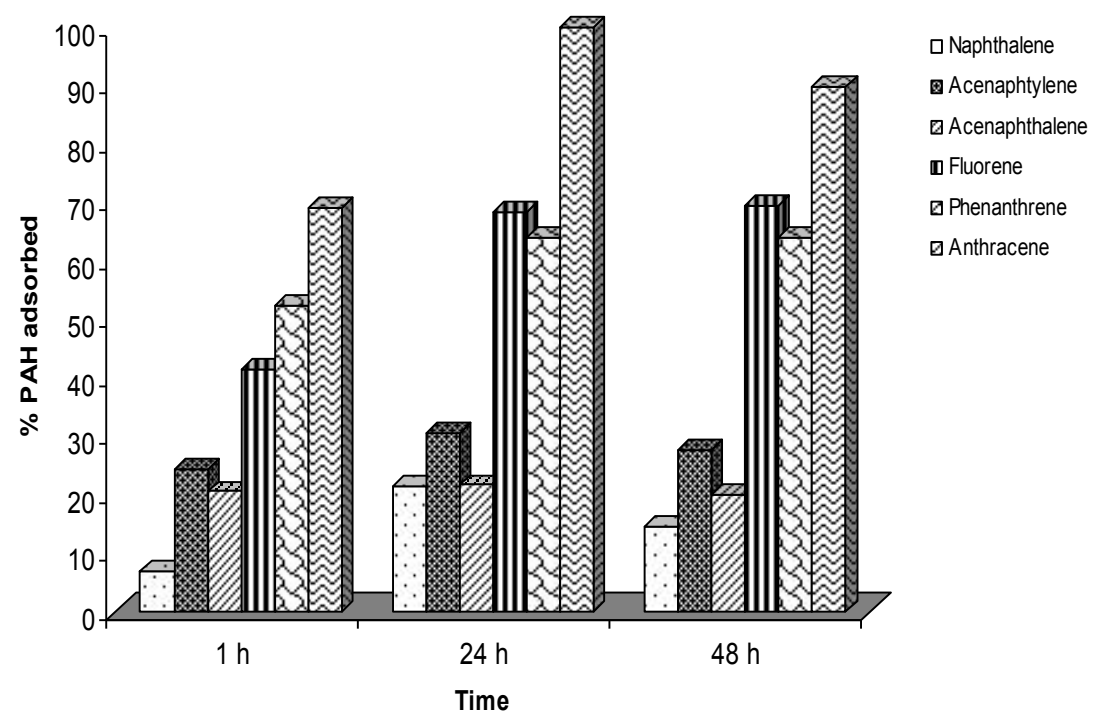

Figure 2. Effect of time on the adsorption of PAHs onto sodium dodecyl sulfate modified Bentonite adsorbent.

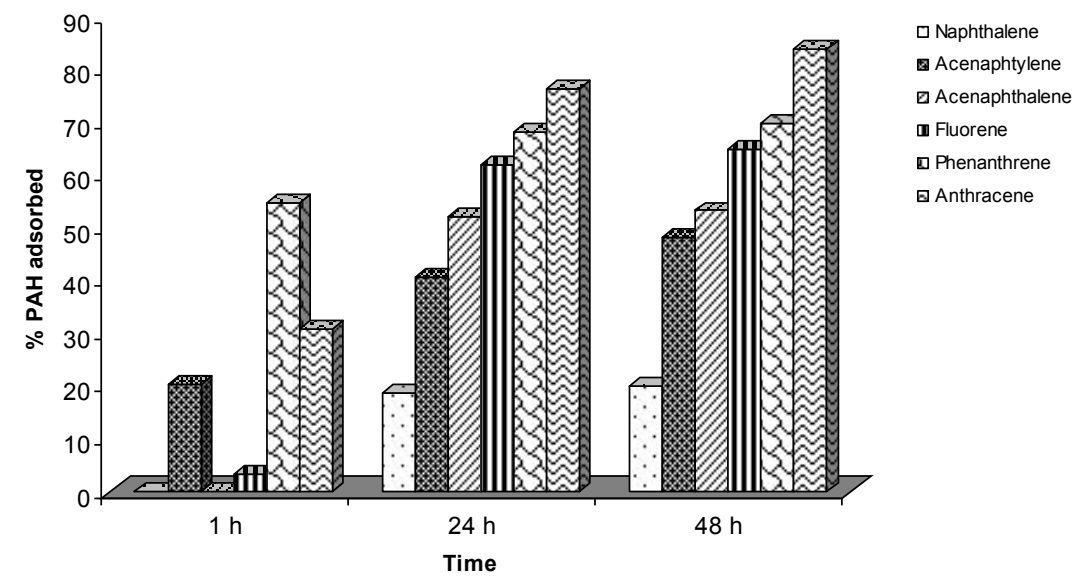

Figure 3. Effect of time on the adsorption of PAHs onto humic acid modified-Bentonite adsorbent. 


\section{CONCLUSION}

A comparison of the efficiency of a new hybrid clay adsorbent (HYCA) versus sodium dodecyl sulfate modified and humic acid modified Bentonite clay for the removal of PAHs from aqueous solution was studied. The new hybrid clay material was observed to show better efficiency and its adsorption of PAHs from aqueous solution was more spontaneous than either modified adsorbents. At $1 \mathrm{~h}$ some of the larger PAH molecules were $\approx 100 \%$ adsorbed onto the new hybrid clay adsorbent as compared with $\approx 62 \%$ and $\approx 76 \%$ for either sodium dodecyl sulfate modified or humic acid modified Bentonite clay adsorbents respectively. The new hybrid clay has a strong potential to replace already existing modified adsorbents used in the removal of PAHs from aqueous solutions.

\section{REFERENCES}

1. Dai, Y.; Niu, J.; Yin, L.; Xu, J.; Xi, Y. J. Hazard. Mater. 2011, 192, 1409.

2. Chu, S.N.; Sands, S.; Tomasik, M.R.; Lee, P.S.; McNeill, V.F. J. Am. Chem. Soc. 2010, 132, 15968.

3. Woo, O.T.; Chung, W.K.; Wong, K.H.; Chow, A.T.; Wong, P.K. J. Hazard. Mater. 2009, $168,1192$.

4. Sabate, J.; Bayona, J.M.; Solanas, A.M. Chemosphere 2001, 44, 119.

5. Niu, J.F.; Sun, P.; Schramm, K.W. J. Photochem. Photobiol. A 2007, 186, 93.

6. Haritash, A.K.; Kaushik, C.P. J. Hazard. Mater. 2009, 169, 1.

7. Krupadam, R.J.; Khan, M.S.; Wate, S.R. Water Res. 2010, 44, 681.

8. Rajec, P.; Galambos, M.; Dano, M.; Rosskopfova, O.; Caplovicova, M.; Hudec, P.; Hornacek, M.; Novak, I.; Berek, D.; Caplovic, L. J. Radioanal. Nucl. Chem. 2015, 303, 277.

9. Gong, Z.Q.; Alef, K.; Wilke, B.M.; Li, P.J. J. Hazard. Mater. 2007, 143, 372.

10. Long, C.; Lu, J.D.; Li, A.M.; Hu, D.B.; Liu, F.Q.; Zhang, Q.X. J. Hazard. Mater. 2008, 150, 656.

11. Yang, K.; Zhu, L.Z.; Xing, B.S. Environ. Sci. Technol. 2006, 40, 1855.

12. Unuabonah, E.I.; Gunter, C.; Weber, J.; Lubahn, S.; Taubert, A. ACS Sustainable Chem. Eng. 2013, 1, 966.

13. Yalçin, T.; Alemdar, A.; Ece, O.I.; Gungor, N. Mater. Lett. 2002, 57, 420.

14. Olu-Owolabi, B.I.; Popoola, D.B.; Unuabonah, E.I. Water, Air, Soil Pollut. 2010, 211, 459.

15. Bi, E.; Schmidt, T.C.; Haderlein, S.B. Environ. Sci. Technol. 2006, 40, 5962.

16. Zeledon-Turuno, Z.C.; Lao-Luque, C.; de las Heras, F.X.C.; Sole-Sardans, M. Chemosphere 2007, 67, 505.

17. Nakata, H.; Kannan, K.; Nasu, T.; Cho, H.S.; Sinclair, E.; Takemura, A. Environ. Sci. Technol. 2006, 40, 4916.

18. Sun, K.; Ran, Y.; Yang, Y.; Xing, B.S. Environ. Sci. Technol. 2008, 42, 1961.

19. Wang, L.; Yang, Z.; Niu, J. Chemosphere 2011, 82, 895.

20. Gaboriau, H.; Saada, A. Chemosphere 2001, 44, 1633.

21. Conte, P.; Zena, A.; Pilidis, G.; Piccolo, A. Environ. Pollut. 2001, 112, 27.

22. Pan, B.; Ghosh, S.; Xing, B. Environ. Sci. Technol. 2007, 41.

23. Terashima, M.; Tanaka, S.; Fukushima, M.J. Environ. Quality 2003, 32, 591.

24. Yuan, M.; Tomng, S.; Zhao, S.; Jia, C.Q. J. Hazard. Mater. 2010, 181, 1115.

25. He, Y.Y.; Wang, X.C. Colloids and Surfaces A: Physicochem. Eng. Aspects 2011, 379, 93.

26. Xiao, F.; Pignatello, J.J. Environ. Sci. Technol. 2015, 49, 906.

27. Unuabonah, E.I.; Adie, G.U.; Onah, L.O.; Adeyemi, O.G. Chem. Eng. J. 2009, 155, 567. 